\title{
Study of Third-Degree Burn Wounds Debridement and Treatment by Actinidin Enzyme Immobilized on Electrospun Chitosan/PEO Nanofibers in Rats
}

\author{
Najmeh Ketabchi 1(D), Rassoul Dinarvand 2(D), Mahdi Adabi 1(i), Mahdi Gholami ${ }^{3(\mathbb{D})}$, Saman \\ Firoozi $^{1}$ (D), Bentolhoda Amanzadi 1 (D), Reza Faridi-Majidi 1,*(D) \\ 1 Department of Medical Nanotechnology, School of Advanced Technologies in Medicine, Tehran University of Medical \\ Sciences, Tehran, Iran \\ 2 Nanotechnology Research Center, Faculty of Pharmacy, Tehran University of Medical Sciences, Tehran, Iran \\ 3 Faculty of Pharmacy, Pharmacology and Toxicology, Tehran University of Medical Sciences \\ * Correspondence: refaridi@sina.tums.ac.ir;
}

Scopus Author ID 55991162500

Received: 2.10.2020; Revised: 22.10.2020; Accepted: 23.10.2020; Published: 25.10.2020

\begin{abstract}
In this study, the actinidin enzyme that was extracted from kiwi fruit was immobilized on a scaffold based on electrospun chitosan nanofibers, and its ability to treat burn wounds was investigated. Afterward, cytotoxicity of the nanofibrous patch and nanofibers with actinidin enzyme was evaluated by MTT test separately on skin fibroblast cells (AGO1522), and their efficacy was investigated on rat model's full-thickness burn wounds. As a result, SEM showed the diameters of the fibers that were in a range of 100-200 nm depending on the electrospinning condition. MTT results confirmed the cell viability is exposing the enzyme and nanofibers. Then evaluating wound closure percentage in animal samples was analyzed by statistical tests. Considering $\mathrm{P}<0 / 05$, a significant difference in the rate of wound closure between the groups was observed. Histopathological assays also showed the accelerating effect of the nanofibrous patch with an enzyme in epithelisation, angiogenesis, collagen deposition, and its effective role in scar formation prevention. In this study, actinidin also showed perfect compatibility with cells, and chitosan could prevent wounds infection. So using this bandage could eliminate the scars and reduce the treatment time.
\end{abstract}

Keywords: actinidin; degree 3 burn; chitosan; wound dressing; nanofiber; electrospinning.

(C) 2020 by the authors. This article is an open-access article distributed under the terms and conditions of the Creative Commons Attribution (CC BY) license (https://creativecommons.org/licenses/by/4.0/).

\section{Introduction}

The primary goal of burn wounds cares to promote and improve the efficiency of wound healing and wound closure through the epithelialization process [1]. But in severe burns, at first, the necrotic tissue should be removed, and then, depending on the severity of the burn, excision surgery may be needed before using topical treatments. Although the topical burns treatments often are based on infection prevention, it does not have a significant effect on tissue recovery $[2,3]$. So, the scar early removal and creating of a clean wound bed is the first step of the wound healing process theoretically, either by epithelialization or auto-grafting, spontaneously.

In recent 20 years, enzymatic elimination of necrotic tissue from severe burns using trypsin, collagenase, and some other proteases [4-7] instead of the routine surgical tissue removal $[8,9]$ and skin drafting [10-12] has attracted 'researchers' attention. Some studies have 
shown that the debridement achieved by collagenase is more effective in creating a perfect and complete clean bed wound rather than scar removal by surgery [13-17].

In this method, scar elimination starts immediately after the wound formation, so it is a noninvasive method without damaging the healthy tissue; in addition, it can lead to necrotic tissue complete removal [13-16].

Another protease enzyme that acts like collagenases is actinidin enzyme, a thiol protease that has a molecular weight of 26,000 and two active proteins $[18,19]$ and is abundant in various kiwi fruit $[19,20]$. Collagenase's effect of actinidin has already been investigated in some researches [21-23]. Some studies have shown that actinidin is not capable of hydrolyzing the natural molecule of collagen, but it hydrolyses atelocollagen that is a partially digested collagen [24]. Figure 1 schematically shows the actinidin enzyme structure with its substrate.
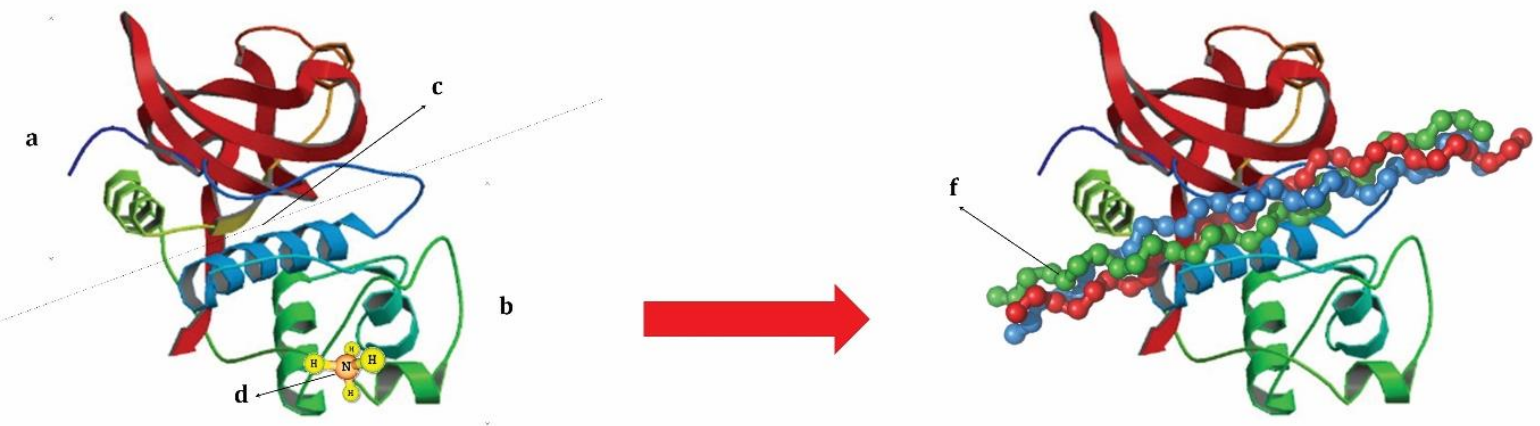

Figure 1. actinidin structure in water, from protein data bank (PDB); (a) Domain 1 made of beta-sheets; (b) domain 2 made of alpha chains; (c) Active site of enzyme; (d) attachment site to the enzyme (ammonium ion); (f) Gelatin fiber Produced from collagen degradation.

More studies about the effect of actinidin on enzymatic hydrolysis of collagen show that actinidin has no significant effect on the perfect collagen molecule [25, 26], but there is a challenge with exposing the burn wounds to actinidin enzyme beneficially.

One of the best dressings that can carry enzymes is an electrospun nanofibrous mat. Electrospun nanofibers have several medical applications such as in drug delivery systems [27, 28], tissue engineering [27, 29], biosensing [27, 30], and wound dressings [31-34]. The nanoporous structure of electrospun mats is efficient for wounds bandage exchange, prevents wound drying, and makes proper control over the wound's humidity. The pores are not large enough to allow bacteria to pass the dressing to the wound $[30,35,36]$. In addition, electrospun nanofibrous mats can promote epithelialization [37, 38] and angiogenesis [38, 39], by simulating Extracellular Matrix (ECM) (e.g., collagen and fibronectin) [38]. Polymeric nanofibers structure also provides an excellent roadmap for cell growth and wound healing, so it will lead to a significant reduction in scar tissue remaining [40, 41].

One of the most popular polymers for this purpose is Chitosan (Cs) that is a natural polysaccharide with its ability of wounds infection inhibition [42, 43] and inflammatory response reduction [41, 44]. Furthermore, chitosan-based nanofibers have a specific vast surface and nano-porous structure that result in more enzyme loading capacity [35, 45].

There are several methods to make nanofibers from chitosan that the most famous of them is the electrospinning technique [31, 46]. In these methods, the polymeric micro/nanofibers can be made by a high voltage source on a rotating cylindrical collector $[31,46]$. Since chitosan is not capable of making integrated thin and long fibers $[40,44,47$ - 
49], blending it with other polymers such as gelatin [50], polymethyl methacrylate (PMMA) [51], polyethylene oxide (PEO) [51] can improve its electrospun nanofibers structure.

Afterward, it is necessary to fix the enzyme molecules on nanofibers without getting any damaged, denatured, and accumulated, which is possible by the covalent immobilization method [34]. The potential covalent band can lead to the enzyme release reduction and causes its stability on nanofibers surface [34, 52]. Also, there is a significant reduction of burst effect in the early hours. As a result, this approach prevents unwanted and unpredictable effects due to the enzyme inclusion in the body. One of the most important effects of the enzyme immobilization on the surface of the nanofibers is its reusability that increases enzyme efficiency several times [53-55]. In addition, the immobilized enzyme can be used in nonaqueous media [56, 57].

In this study, electrospun Cs/PEO nanofibrous mats were prepared with actinidin enzyme, and then it was evaluated by cell viability assay. Finally, the dressings were tested on animal models, and the healing process was investigated with the histopathological assay, respectively. All results were compared with the same scaffold without the enzyme.

\section{Materials and Methods}

Chitosan (low molecular weight: 2.5 KD, Easter group (Dong Chen) Co. Ltd) and PEO (MW 900 KD, Acros Organics Co) were used as received. Glacial acetic acid (AcOH, Merck Chemical) was used as a solvent and Glutaraldehyde (Panreac, Spain) as a crosslinking agent. The chitosan/PEO solutions were electrospun to nanofibers, using Electroris ${ }^{\circledR}$ (FNM Ltd., Iran, www.fnm.ir) as an electrospinning instrument, actinidin (from kiwi fruit, Kermanshah university of medical sciences, Iran). 1-Ethyl-3-(3-dimethylaminopropyl) carbodiimide (EDC) and N-Hydroxysuccinimide (NHS) (Merck, Germany) were also used.

RPMI medium and Fetal Bovine Serum (FBS) (Gibco, USA) and MTT (3-[4, 5dimethylthiazol-2-yl]-2, 5-diphenyl-tetrazolium bromide) (Sigma-Aldrich, USA) with human fibroblast (AGO-1522) (supplied by National Cell Bank of Iran, Pasteur Institute of Iran) were used in MTT test. Ketamine 10\% (v/v) and xylazine 2\% (v/v) (alfasan, Holand) and Wistar male rats were bought for in vivo test (Faculty of Pharmacy, Pharmacology, and Toxicology, Tehran University of Medical Sciences, Iran).

\subsection{Methods.}

2.1.1. Fabrication of the electrospun nanofibrous patch.

Cs and PEO were dissolved in aqueous glacial acetic acid 80\% (v/v), separately (both $2.5 \% \mathrm{w} / \mathrm{v}$ ) under gentle stirring overnight and at room temperature to form homogeneous solutions. As shown in Table 1, to produce Cs/PEO nanofibers, the Cs, and PEO solutions were blended together with different proportions. [46]. Then, every resulted solution was put into a $5 \mathrm{~mL}$ syringe with a metallic blunt-ended $18 \mathrm{G}$ needle as a nozzle, which was connected to a high voltage power supply. Finally, a piece of spun-bond was covered by the rotating collector of the Electroris ${ }^{\circledR}$ device as a substrate layer (Table 1). The nanofibrous mats were made on the substrate and then were dried per $24 \mathrm{~h}$ at room temperature. Then the fibrous membrane on the substrate was investigated for the diameter evaluation by Scanning Electron Microscopy (SEM). So the patch with acceptable monodispersity and the average diameter was chosen [46]. 
Table 1. Polymer solutions and optimizing conditions for the electrospinning process.

\begin{tabular}{c|c|c|c|c}
\hline \multirow{3}{*}{ samples } & \multicolumn{2}{|c|}{ 'Solution's parameters } & \multicolumn{2}{c}{ 'Electrospinning's set up parameters } \\
\cline { 2 - 5 } & $\begin{array}{c}\text { Total polymers } \\
\text { concentration (wt } \%)\end{array}$ & $\begin{array}{c}\text { Cs to PEO ratio } \\
\text { (Cs:PEO) }\end{array}$ & $\begin{array}{c}\text { Nozzle to collector } \\
\text { distance(mm) }\end{array}$ & The rate \\
\hline A & 2.5 & $9: 1$ & 90 & 0.5 \\
\hline B & 2.5 & $8: 2$ & 80 & 1.0 \\
\hline C & 2.5 & $8: 2$ & 80 & 1.5 \\
\hline D & 2.5 & $8: 2$ & 70 & 1.2
\end{tabular}

2.1.2. Immobilization of actinidin enzyme on a polymeric mat.

Actinidin was immobilized on the optimized Cs/PEO nanofibrous patches by EDC/NHS activation procedure. Appropriate amounts ( $4 \times 4$ centimeter, $3 \pm 0.3$ gram) of the nanofibrous patch with its fabric substrate were cut out and sterilized by ultraviolet radiation. These were held in glutaraldehyde vapor overnight to get crosslinked favorably. After that, they were cleaned with deionized water and then rinsed with PBS buffer $(\mathrm{pH}=7)$. Then the patches were submerged into EDC/NHS solution (in PBS buffer, the molar ratio of EDC to $\mathrm{NHS}=1: 1)$ and shaken gently for six $\mathrm{h}$ at room temperature [59]. The activated patches were taken out and washed several times with PBS buffer $(\mathrm{pH}=5.5)$. Afterward, several concentrations from actinidin enzyme solution were prepared (from 5\% to 50\% (v/v) in PBS buffer, $\mathrm{pH}=5.5$ ), the patches were immersed in solutions and kept at the temperature of $4{ }^{\circ} \mathrm{C}$ in a shaking water bath for an hour. Finally, the patches were taken out and thoroughly rinsed with deionized water and got dried at room temperature.

\subsubsection{Cytotoxicity evaluation.}

Fibroblasts are collagen-producing cells in mammalians and are the major cells interfering in wound closure and healings. The cell viability of fibroblast that was exposed to the nanofibrous mats was evaluated by MTT assay (3-(4,5-Dimethylthiazol- 2-yl)-2,5diphenyltetrazolium bromide) based on a procedure that was adapted from the ISO 10993-5 standard test method. The mats were punched and placed into 96-well plates, then sterilized with UV radiation for two h. Human fibroblasts (AGO 1522) in RPMI medium supplemented with $10 \%$ FBS were seeded in the bottom of the wells. Then the plate was incubated at the temperature of $37^{\circ} \mathrm{C}$ for $24 \mathrm{~h}$, and furthermore, the culture medium in the wells was removed and replaced with $100 \mu 1$ MTT solution $(0 / 5 \mathrm{mg} / \mathrm{ml})$. The plate was re-incubated for four $\mathrm{h}$, and then the MTT solutions were removed with $100 \mu$ isopropanol to dissolve the formazan crystals that have been created in living cells., The absorbance of the formazan solutions was studied by a plate reader (awareness technology, Stat fax2100, USA) at $490 \mathrm{~nm}$ to determine the viability percentage of the sample cell. The cell-free culture medium, RPMI, was defined as $100 \%$ negative control $[31,60]$.

\subsubsection{Wound healing evaluation.}

As an animal model, 30 male Wistar rats $(250-300 \mathrm{~g})$ were randomized in five groups that each group was included 6 in rats. Animals were anesthetized by IP injection of Ketamine and Xylazine, and then their hairs on the dorsal skin area were shaved. After that, a fullthickness third-degree standard burn wound was made on the shaved area of each rat. The wounds were covered by prepared coatings and the dressings that are replaced daily with new covers until two weeks. Each wound area was observed every day and pictured with a digital camera. The wounds closure percentage that determined the wound healing effect of samples was evaluated formulas follow: 


\section{$\mathrm{WCR}=(\mathrm{A} 0-\mathrm{At}) / \mathrm{A} 0 \times 100$}

Where $\mathrm{A} 0$ is the initial wound area, and at is the wound area at a time.

\subsubsection{Histopathological analysis.}

The wound tissues were taken from one sample of each group in 3, 7, and 15 days. The samples were fixed in formalin of $10 \%$ solution; they were dehydrated by ethanol and embedded in paraffin. Then, they were cut into five $\mu \mathrm{m}$ thick cross sections and were stained by Hematoxylin and Eosin (H\&E). Histological analysis was done under optical microscopy conditions.

\section{Results and Discussion}

\subsection{Fabrication and characterization of Cs/PEO electrospun nanofibers.}

According to Table 1, $4 \mathrm{Cs} / \mathrm{PEO}$ solutions blend (both $2.5 \% \mathrm{w} / \mathrm{w}$ ) was prepared to get electrospun. Electrospinning instrumental parameters were changed in turn, and differences in fibers morphology have been monitored by Scanning Electron Microscopy (SEM) images to find optimum p condition. Then SEM images (Figure 2) were investigated by semAfore5.21 software. The optimum patch should have uniform bead-free nanofibers with the lowest both average diameter and fibers diameter distribution. Since the mat with the lowest frequency distribution had the most monodisperse nanofibers, so the enzyme molecules can be loaded more uniformly on these nanofibers [61, 62]. According to Figure 2, the most monodisperse nanofibers with the least average diameter $(125.76 \mathrm{~nm})$ were found in sample $\mathrm{D}$ as the optimized patch.

Then the chosen mat (sample $d$ in Figure 2) got crosslinked by holding in glutaraldehyde vapor overnight. SEM images demonstrate that the nanofibers have been well crosslinked without getting any damages in their structures while immersing in a buffer (Figure $3)$.

\subsection{Actinidin enzyme immobilization on the electrospun mats.}

In order to determine more appropriate enzyme concentration to immobile on the nanofibrous mats, different actinidin concentrations from $5 \%$ to $50 \%(\mathrm{v} / \mathrm{v})$ were prepared and immobilized on similar mats. Then the mats were cleaned with buffer, and the buffers were tested by Bradford assay to find molecules enzyme in them (Figure 4). Resulted curves showed that the enzyme's concentrations that are lower than $20 \%$ had been completely attached to the fibers (the log part of the graph). But all the enzyme molecules in the concentration between 20-25 (wt \%) cannot bound to nanofibers (where the graph has been linear) and have been cleaned by the buffer. So, $20 \%$ actinidin enzyme concentration was chosen for immobilization on the surface of electrospun nanofibrous patches.

\subsection{Biological safety of actinidin enzyme loaded mats.}

Actinidin enzymes biological safety was evaluated by MTT assay on AGO1522 cell line (human skin fibroblasts). Then the sample absorbance was obtained from a plate reader and achieved data were studied by SPSS software and One Way ANOVA Tukey test (Figure $5)$. 

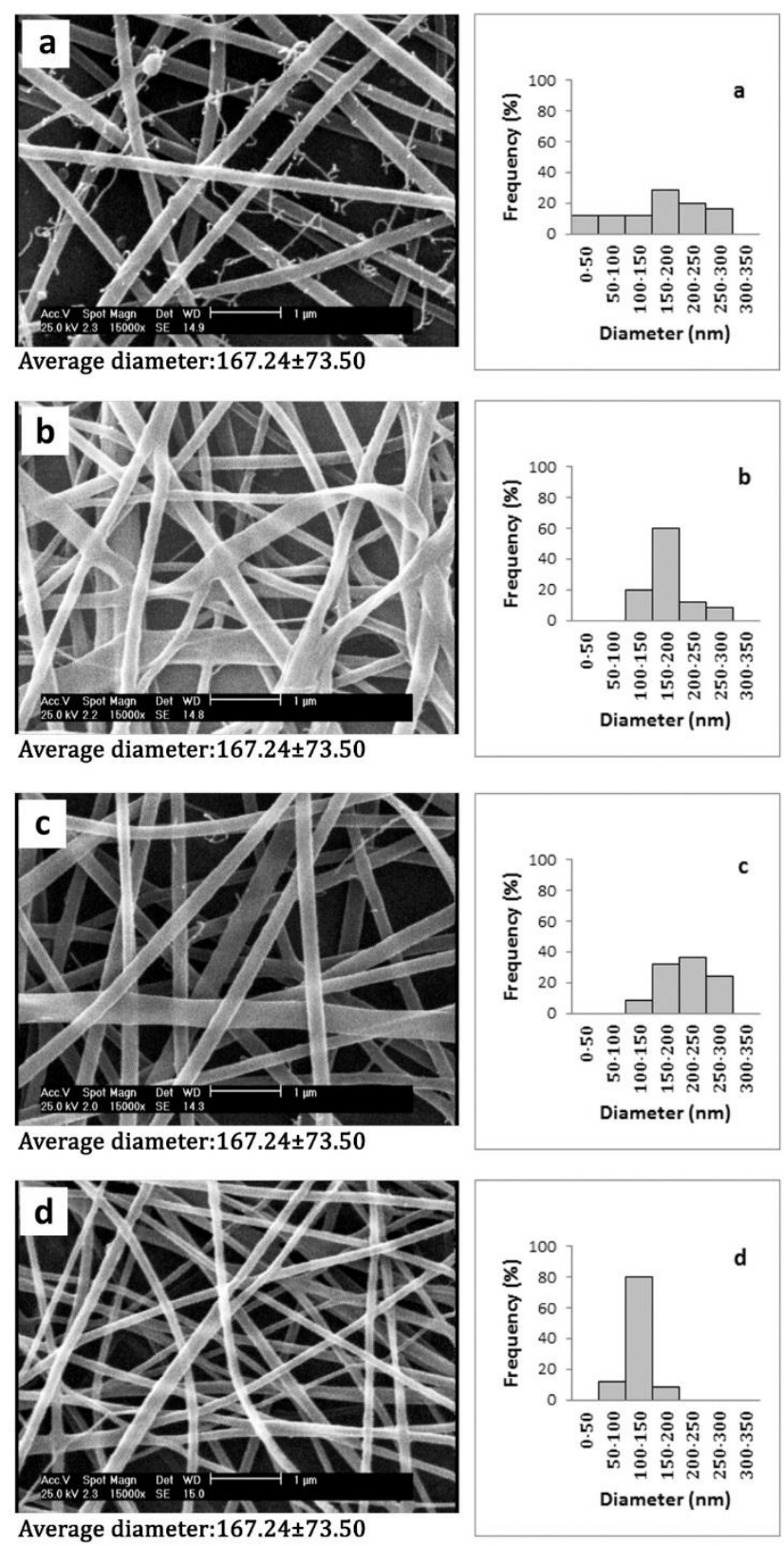

Figure 2. SEM images from some patches are made by the electrospinning technique. The mean diameters were measured by SemAfore 5.21 software. The frequency distribution of nanofibers diameter in patches has been illustrated in the right of any image.
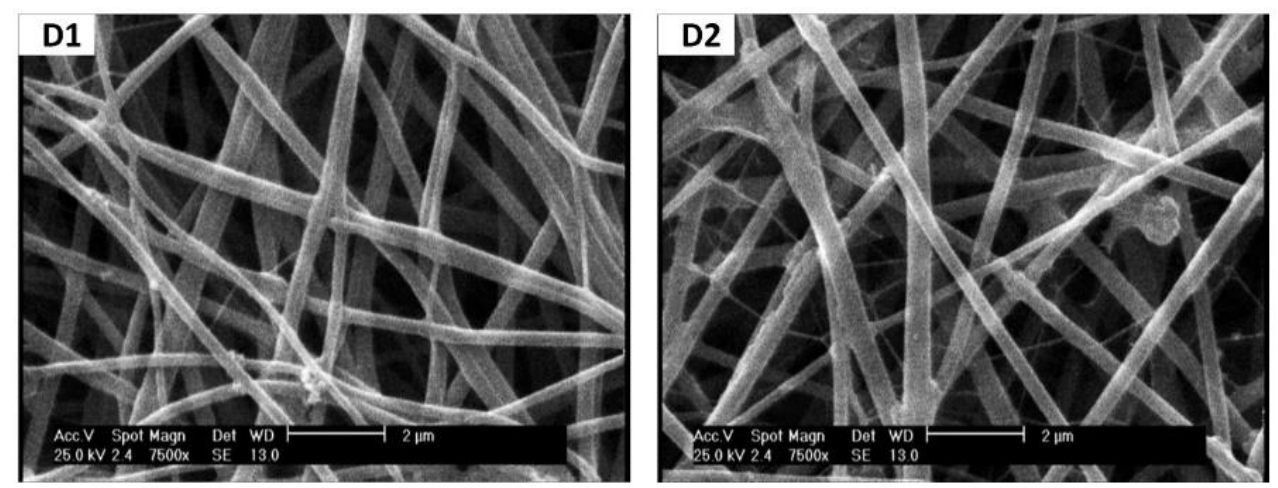

Figure 3. Cs/PEO nanofibers crosslinked with Glutaraldehyde10\% vapour; D1)Crosslinked mat after $1 \mathrm{~h}$ immersion in PBS $1 \mathrm{M}\left(\mathrm{pH}=7,37^{\circ} \mathrm{C}\right)$; D2)Crosslinked mat after $24 \mathrm{~h}$ immersion in $\mathrm{PBS} 1 \mathrm{M}\left(\mathrm{pH}=7,37^{\circ} \mathrm{C}\right)$ 


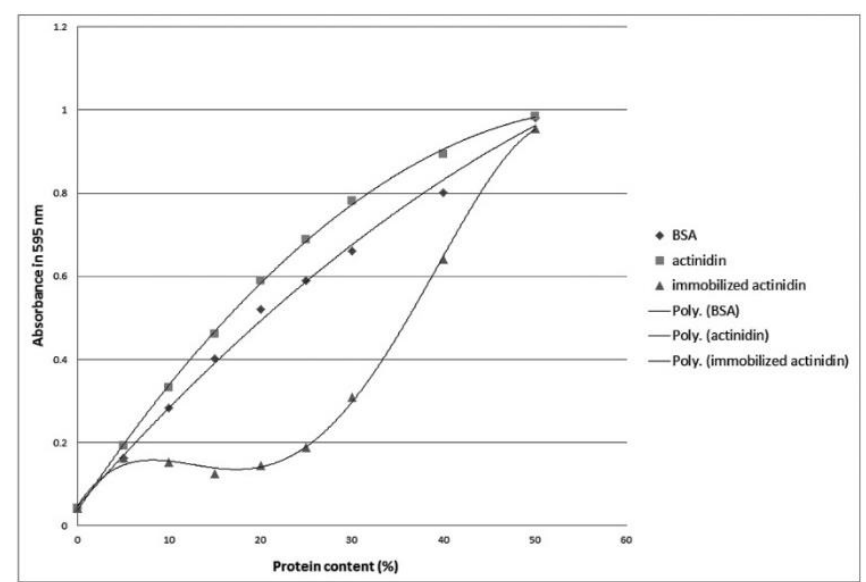

Figure 4. Bradford assay chart. The protein percentage in the initial solution has changed from 0-50\% (horizontal axis). After the enzyme was immobilized with each concentration and the mat was washed with PBS buffer, the optical absorbance of samples (Vertical axis) have been read from washing solutions and plotted with the BSA standard curve and free actinidin. As shown here, the protein with a concentration lower than $20 \%$ has immobilized on the mats completely.

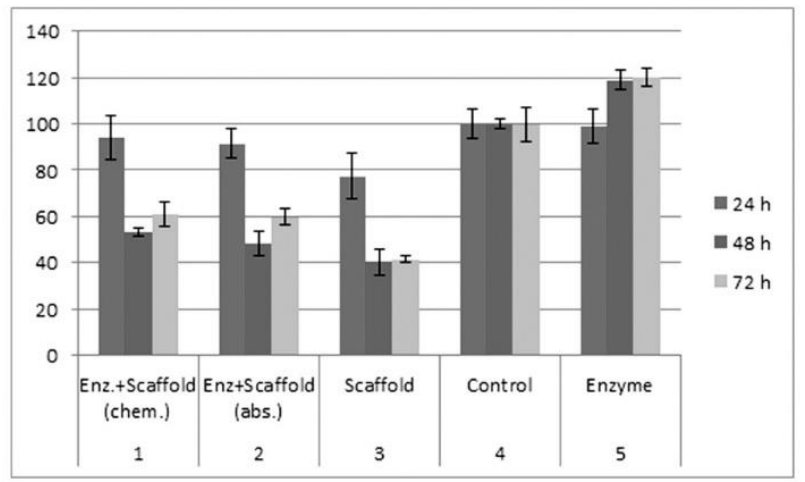

Figure 5. MTT test results. Cell viability percentage in 5 groups investigated with MTT test on the AGO1522 cell line. Groups are 1) Nanofibrous mat crosslinked with GA and actinidin immobilized by EDC/NHS; 2) Nanofibrous mat crosslinked with GA and actinidin absorbed physically; 3. Nanofibrous mat crosslinked with GA; 4) CONTROL; 5) actinidin enzyme

In the first $24 \mathrm{~h}$, the mean difference was significant at the 0.05 level between only group 3 and group 4 (control), which implies a cell viability reduction. In $48 \mathrm{~h}$ and $72 \mathrm{~h}$, groups 1,2 , and 3 had significant differences, too. There were no significant differences between groups 1 and 2, so it can be concluded that EDC/NHS cross-linkers have eliminated from the patch's structure completely. All these results demonstrate that however electrospun crosslinked chitosan/PEO patch have a toxic effect on fibroblasts, but considering related studies implies the cytotoxicity of these nanofibers, and it can be due to the cross-linker used glutaraldehyde [63-65], and even Cs/PEO electrospun patch that has reported safe in clinical applications $[40,66,67]$. It has shown that the actinidin enzyme not only has no cytotoxicity but also induce the cells more viability and proliferation. Due to the results, it can be concluded that the electrospun Cs/PEO patch that is loaded with the actinidin enzyme has no significant cytotoxicity.

\subsection{Animal evaluation.}

The enzyme loaded electrospun patches have an effect on burn wound's healing and necrotic tissue debridement, and it was evaluated by a dorsal deep burn wound model of a rat. The round full-thickness burn wounds were made by $2.0 \mathrm{~cm}$ diameters on the dorsal side of 30 
Wistar male rats. Then the wounds were covered by different bandages in five different groups: The electrospun patch with and without the enzyme, silver sulfadiazine $1 \%$ ointment as a routine burn treating medicine, fresh kiwi fruit puree as the enzyme source, and sterile gauze as control. All bandages were replaced daily (every $24 \mathrm{~h}$ ), and pictures were taken from the wounds (Figure 6). After 15 days, the pictures were analyzed by Image $\mathrm{J}$ software to evaluate the reduction of the percentage in wound areas. Figure 7 demonstrates the changes in the wound area closure percentage.

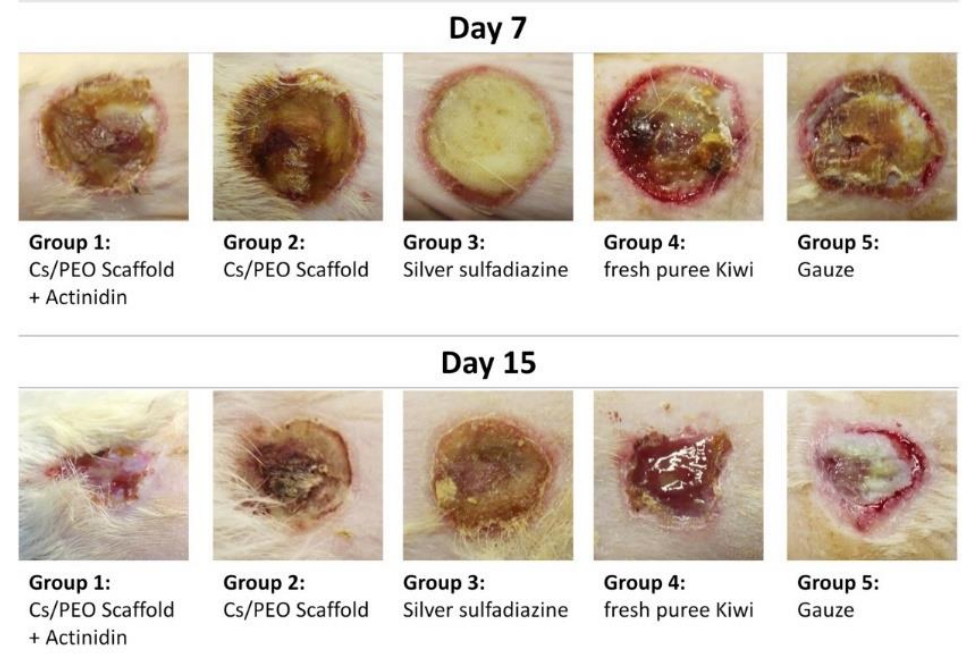

Figure 6. In vivo results. Pictures captured by a digital camera in days 7 and 15 from the wound treated with different bandages remarked in blew of them.

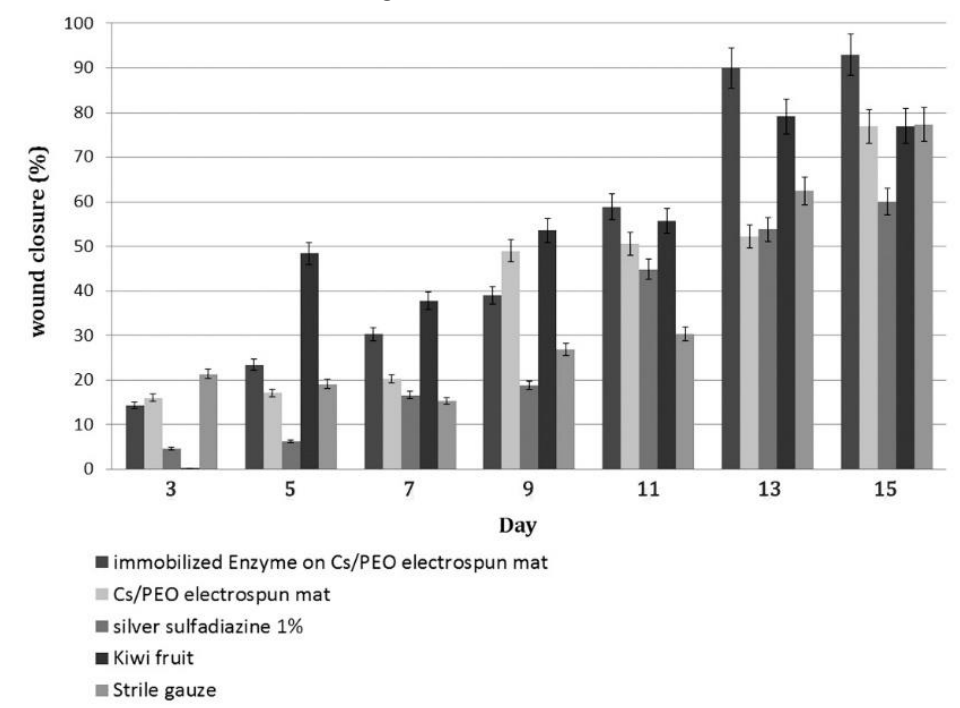

Figure 7. Wound closure percentage in rats treated for 15 days. All groups have been determined below the chart. The groups are comparable with themselves and each other. The chart shows a wound closure percentage in odd days from day 3 to 15 .

According to Figure 7, the study of the wounds appearances during the healing period showed that in group 1 (nanofibrous Cs/PEO patch containing immobilized actinidin enzyme) after 10 days, debridement and necrotic tissue digestion were visible, and hair growth was started in this area. There was no infection and bleeding in this group. In comparison, group 2 (nanofibrous Cs/PEO scaffold without the enzyme) showed a slower recovery trend. Similarly, there was no infection in this group too, but there was a few bleeding from the 9 th day. Whereas in group 3 (bandage with Silver sulfadiazine ointment that was covered by sterile gauze) despite reduced inflammation with no infection, wound adhesion to the bandage and bleeding were observed. In group 4 (fresh puree of Kiwi fruit covered with sterile gauze as wound 
dressing), despite the fast and complete debridement on the 5th day, severe infection and bleeding were seen. It may be due to the acidic nature of kiwi (its $\mathrm{pH}$ was about 3.5). In group 5 (bandage with sterile gauze), there was no debridement, so unpleasant features of the wounds, infection of the wounds, wound adhesion to the bandage, and bleeding while bandage changing was seen. It seems that the chitosan patch, besides careering the enzyme, is responsible for lack of adhesion and infection, so it can have an effect on the therapeutic properties of the bandage containing immobilized enzyme on nanofibrous Cs/PEO patch.

\subsection{Histopathological examinations.}

Histological studies in 3, 7, and 15 days were done on skin tissues that were taken from the wound of one rat from each group and fixed in $10 \%$ neutral formalin solution.

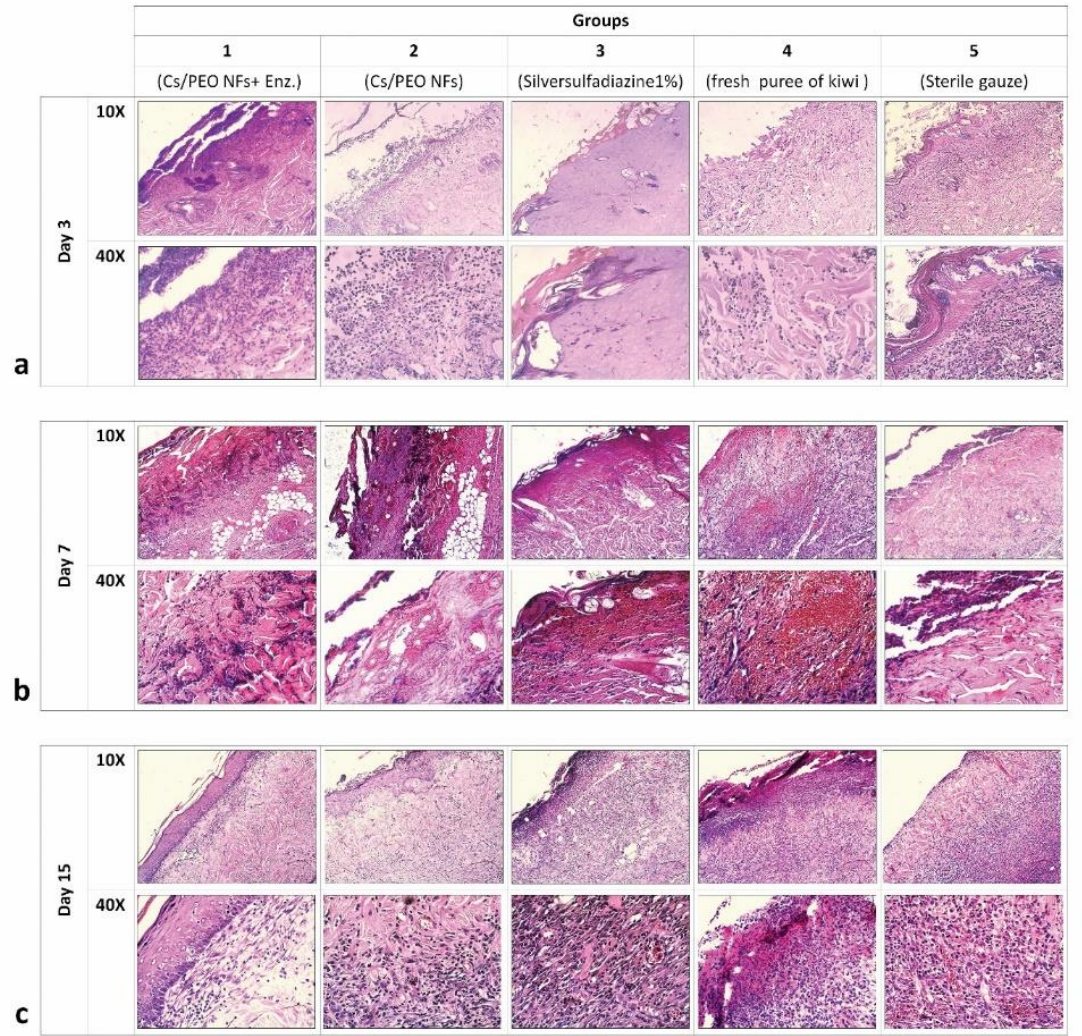

Figure 8. Histopathological images were taken by optical microscopy after H\&E staining. The tissue samples were taken on days 3,7 , and 15 , as shown in the picture. The vertical axis indicates samples were taken on day 3 (Fig. 8-a), day 7 (Fig. 8-b), and day 15 (Fig. 8-c). Every box contains pictures with 10X and 40X magnification. The horizontal axis determines tested groups from 1 to 5 and related pictures below them.

Day 3: As the pictures show (Figure 8-a), on the third day, exudate is visible in all the groups. But it is negligible in group 4. Inflammatory cells are also visible in all 5 groups, but in group 3 are a few in comparison. Angiogenesis, collagen fibers deposition, and epithelization have not been seen in any group. The enzyme loaded patch have less exudate in comparison with the control group and has attracted fewer inflammatory cells, although it is more than other groups.

Day 7: regarding Figure 8-b, there is an inflammatory exudate yet, and relatively is similar in all the groups. There was no exudate in groups except in groups 1 and 4. Inflammatory cells that are numerous in groups 4 and 1 are visible in all the groups too, but the most were in group 4. The severe bleeding of the tissue is quite evident in the pictures of group 4 and is also seen rarely in group 3 (In the form of a number of sporadic red blood cells in the 
tissue). The angiogenesis has started in groups 1,2, and 4, and epithelization has begun in group 1. Collagen deposition can be observed in group 1, too. It indicates that the used nanofibrous patch has accelerated the angiogenesis process, and the nanofibrous patch with actinidin enzyme also has taken a role in epithelization and collagen production.

Day 15: As shown in Figure 8-c, on the last day in group 1 epithelization process has been completed, contrary to other groups. In groups 3 and 4, this process is in its first levels. Angiogenesis has been accomplished in all groups except group 4. Collagen deposition is visible in groups 1,2, and 5. There is an inflammatory exudate in groups 2 and 3 yet, and there are inflammatory cells also in group 4 . Thus, the actinidin enzyme immobilized on electrospun nanofibrous patch has been able to complete and expedite third-degree burn wounds, without remaining irregularly deposited collagen fibers and eschar, as a result.

\section{Conclusions}

In this study, Cs/PEO nanofibrous mats by electrospinning technique are prepared and characterized by SEM microscopy. Nanofibers with Glutaraldehyde vapor are crosslinked, and then the actinidin enzyme that is extracted from kiwi fruit is immobilized, and its activity in different conditions is investigated.

The results that are obtained from the MTT assay show that the AGO1522 cell line has extra viability in enzyme existence. The results also indicate that glutaraldehyde cannot be removed completely from crosslinked mats, so it can have an effect on the safety of the Cs/PEO scaffold. But finally, the safety of the patch with immobilized actinidin is acceptable.

This dressing effect on animal models shows that it is able to eliminate infection, bleeding, adhesion to the bandage, and as a result, the pain that is caused by it. The wound closure and the wound healing trend confirm this conclusion.

Histopathological studies indicate that $\mathrm{Cs} / \mathrm{PEO}$ electrospun dressing is able to make an excellent bed for burn wounds healing by accelerating epithelization, angiogenesis, collagen fibers deposition, and the most important very effective prevention of scar formation. Eventually, nanofibrous chitosan-based scaffolds with actinidin enzyme immobilize on it and can be proposed as an effective therapeutic product for full-thickness burn wounds healing.

\section{Funding}

This research was funded by Tehran University of Medical Sciences and Health Services (TUMS), grant no. 27607. https://search.crossref.org/funding, any errors may affect your future funding.

\section{Acknowledgments}

The authors also appreciate the scientific support offered by Professor Ali Mostafaie and Dr. Shahram Parvaneh from Medical Biology Research Center, Kermanshah University of Medical Sciences, for their help with using the actinidin enzyme.

\section{Conflicts of Interest}

The authors declare no conflict of interest. 


\section{References}

1. Boateng, J.S.; Matthews, K.H.; Stevens, H.N.E.; Eccleston, G.M. Wound healing dressings and drug delivery systems: a review. J. Pharm. Sci. 2008, 97, 2892-2923, https://doi.org/10.1002/jps.21210.

2. Brunicardi, F.C. 'Schwartz's Principles of Surgery. McGraw-Hill Education, 2015; pp 227-236.

3. Nuutila, K.; Grolman, J.; Yang, L.; Broomhead, M.; Lipsitz, S.; Onderdonk, A.; Mooney, D.; Eriksson, E. Immediate Treatment of Burn Wounds with High Concentrations of Topical Antibiotics in an Alginate Hydrogel Using a Platform Wound Device. Adv Skin Wound Care 2020, 9, 48-60, https://doi.org/10.1089/wound.2019.1018.

4. Jung, W.; Winter, H. Considerations for the use of Clostridial collagenase in clinical practice. Clin Drug Investigs. 1998, 15, 245-252, https://doi.org/10.2165/00044011-199815030-00009.

5. Soroff, H.S.; Sasvary, D.H. Collagenase ointment and polymyxin B sulfate/bacitracin spray versus silver sulfadiazine cream in partial-thickness burns: a pilot study. J Burn Care Res. 1994, 15, 13-17, https://doi.org/10.1097/00004630-199401000-00003.

6. Dadras, M.; Wagner, J.M.; Wallner, C.; Sogorski, A.; Sacher, M.; Harati, K.; Lehnhardt, M.; Behr, B. Enzymatic debridement of hands with deep burns: a single center experience in the treatment of 52 hands. $J$ Plast Surg Hand Surg. 2020, 54, 1-5, https://doi.org/10.1080/2000656X.2020.1755298.

7. Salmerón-González, E.; García-Vilariño, E.; Pérez-del-Caz, M.D.; Sánchez-García, A.; Valverde-Navarro, A.A. Instantaneous specific burn debridement with an enzymatic debriding agent: A new resource for the treatment of burns. Plast Surg Nurs. 2019, 39, 18-21, https://doi.org/10.1097/PSN.0000000000000250.

8. Cope, O.; Langohr, J.L.; Moore, F.D.; Webster Jr, R.C. Expeditious care of full-thickness burn wounds by surgical excision and grafting. Ann. Surg. 1947, 125.

9. Janžekovic, Z. A new concept in the early excision and immediate grafting of burns. J. Trauma Acute Care Surg. 1970, 10, 1103-1108.

10. Ranjbarvan, P.; Soleimani, M.; Samadi Kuchaksaraei, A.; Ai, J.; Faridi Majidi, R.; Verdi, J. Skin regeneration stimulation: the role of PCL-platelet gel nanofibrous scaffold. Microsc. Res. Tech. 2017, 80, 495-503, https://doi.org/10.1002/jemt.22821.

11. Plichta, J.K.; Holmes, C.J.; Gamelli, R.L.; Radek, K.A. Local burn injury promotes defects in the epidermal lipid and antimicrobial peptide barriers in human autograft skin and burn margin: implications for burn wound healing and graft survival. J Burn Care Res. 2017, 38, e212-e226, https://doi.org/10.1097/BCR.0000000000000357.

12. Smolle, C.; Brinskelle, P.; Steiner, A.; Schintler, M.; Kamolz, L.-P. Skin graft fixation in severe burns: use of topical negative pressure. 2017, https://doi.org/10.1007/15695_2017_24.

13. Perlmutter, A.L.; LEAMAN, D.H. Composition, system and method for treating skin, 2017, Google Patents.

14. Husain, Q. Nanocarriers Immobilized Proteases and Their Industrial Applications: An Overview. J. Nanosci. Nanotechnol. 2018, 18, 486-499, https://doi.org/10.1166/jnn.2018.15246.

15. Chen, Y.; Xu, H.; Huang, L.T.; Wenquan, S.; Wan, H. Method for enzymatic treatment of tissue products. 2018, Google Patents.

16. Özcan, C.; Ergün, O.; Çelik, A.; Çördük, N.; Özok, G. Enzymatic debridement of burn wound with collagenase in children with partial-thickness burns. Burns. 2002, 28, 791-794, https://doi.org/10.1016/S0305-4179(02)00191-2.

17. Hoa Bach, T.M.; Pham, T.H.; Dinh, T.S.; Takagi, H. Characterization of collagenase found in the nonpathogenic bacterium Lysinibacillus sphaericus VN3. Biosci. Biotechnol. Biochem. 2020, 1-10, https://doi.org/10.1080/09168451.2020.1799748.

18. Lewis, D.A.; Luh, B. Application of actinidin from kiwifruit to meat tenderization and characterization of beef muscle protein hydrolysis. J. Food Biochem. 1988, 12, 147-158, https://doi.org/10.1111/j.17454514.1988.tb00368.x.

19. Kazem, R.A.; Habeeb, A.W. Extraction And Purification Of Enzyme Actinidin From Kiwi Fruit (Actinidia Chinensis). Plant Arch. 2020, 20, 298-302.

20. Boland, M.J.; Hardman, M.J. Kinetic studies on the thiol protease from Actinidia chinensis. FEBS Lett. 1972, 27, 282-284, https://doi.org/10.1016/0014-5793(72)80641-0.

21. Mostafaie, A.; Bidmeshkipour, A.; Shirvani, Z.; Mansouri, K.; Chalabi, M. Kiwifruit actinidin: a proper new collagenase for isolation of cells from different tissues. Appl. Biochem. 2008, 144, 123-131, https://doi.org/10.1007/s12010-007-8106-y.

22. Yarani, R.; Mansouri, K.; Mohammadi-Motlagh, H.R.; Bakhtiari, M.; Mostafaie, A. New procedure for epidermal cell isolation using kiwi fruit actinidin, and improved culture of melanocytes in the presence of leukaemia inhibitory factor and forskolin. Cell Prolif. 2013, 46, 348-355, https://doi.org/10.1111/cpr.12028.

23. Shirvani, F.Z.; Mostafaei, A.L.I.; Mansouri, K.; Bidmeshkipour, A. Paper: Actinidin a new collagenase for isolation and peimary culture of thymic epithelial cells from rat thymus. Cell Journal 2009, 11.

24. Shirvani Farsani, Z.; Mansouri, K.; Bidmeshkipour, A.; Mostafaie, A. Isolation and Primary Culture of Rat Hepatocytes Using Kiwifruit Actinidin. Scientific Journal of Hamedan University of Medical Science \& Health Services 2007, 14, 16-22. 
25. Sugiyama, S.; Ohtsuki, K.; Sato, K.; Kawabata, M. Enzymatic properties, substrate specificities and pHactivity profiles of two kiwifruit proteases. J. Nutr. 1997, 43, 581-589, https://doi.org/10.3177/jnsv.43.581.

26. Morimoto, K.; Kunii, S.; Hamano, K.; Tonomura, B.i. Preparation and structural analysis of actinidainprocessed atelocollagen of yellowfin tuna (Thunnus albacares). Biosci. Biotechnol. Biochem. 2004, 68, 861867, https://doi.org/10.1271/bbb.68.861.

27. Sill, T.J.; von Recum, H.A. Electrospinning: applications in drug delivery and tissue engineering. Biomaterials. 2008, 29, 1989-2006, https://doi.org/10.1016/j.biomaterials.2008.01.011.

28. Mehraz, L.; Nouri, M.; Namazi, H. Electrospun silk fibroin/ $\beta$-cyclodextrin citrate nanofibers as a novel biomaterial for application in controlled drug release. Int. J. Polym. Mater. 2020, 69, 211-221, https://doi.org/10.1080/00914037.2018.1552865.

29. Singh, Y.P.; Dasgupta, S.; Nayar, S.; Bhaskar, R. Optimization of electrospinning process \& parameters for producing defect-free chitosan/polyethylene oxide nanofibers for bone tissue engineering. Int. J. Polym. Mater. 2020, 31, 781-803, https://doi.org/10.1080/09205063.2020.1718824.

30. Supraja, P.; Singh, V.; Vanjari, S.R.K.; Singh, S.G. Electrospun CNT embedded ZnO nanofiber based biosensor for electrochemical detection of Atrazine: a step closure to single molecule detection. Microsyst. Nanoeng. 2020, 6, 1-10, https://doi.org/10.1038/s41378-019-0115-9.

31. Mirzaei, E.; Faridi-Majidi, R.; Shokrgozar, M.A.; Asghari Paskiabi, F. Genipin crosslinked electrospun chitosan-based nanofibrous mat as tissue engineering scaffold. Nanomed. J. 2014, 1, 137-146, https://doi.org/10.7508/NMJ.2014.03.003.

32. Esnaashari, S.S.; Rezaei, S.; Mirzaei, E.; Afshari, H.; Rezayat, S.M.; Faridi-Majidi, R. Preparation and characterization of kefiran electrospun nanofibers. Int. J. Biol. Macromol. 2014; 70, 50-56, https://doi.org/10.1016/j.ijbiomac.2014.06.014.

33. Ghaffari-Bohlouli, P.; Hamidzadeh, F.; Zahedi, P.; Shahrousvand, M.; Fallah-Darrehchi, M. Antibacterial nanofibers based on poly (l-lactide-co-d, l-lactide) and poly (vinyl alcohol) used in wound dressings potentially: A comparison between hybrid and blend properties. J. Biomater. Sci. Polym. Ed. 2020, 31, 219243 https://doi.org/10.1080/09205063.2019.1683265.

34. Li, W.; Cicek, N.; Levin, D.B.; Logsetty, S.; Liu, S. Bacteria-triggered release of a potent biocide from coreshell polyhydroxyalkanoate (PHA)-based nanofibers for wound dressing applications. J. Biomater. Sci. Polym. Ed. 2020, 31, 394-406, https://doi.org/10.1080/09205063.2019.1693882.

35. Huang, Z.-M.; Zhang, Y.Z.; Kotaki, M.; Ramakrishna, S. A review on polymer nanofibers by electrospinning and their applications in nanocomposites. Compos Sci Technol. 2003; 63, 2223-2253, https://doi.org/10.1016/S0266-3538(03)00178-7.

36. Adeli, H.; Khorasani, M.T.; Parvazinia, M. Wound dressing based on electrospun PVA/chitosan/starch nanofibrous mats: Fabrication, antibacterial and cytocompatibility evaluation and in vitro healing assay. Int. J. Biol. Macromol. 2019, 122, 238-254, https://doi.org/10.1016/j.ijbiomac.2018.10.115.

37. Acevedo, C.A.; Sánchez, E.; Orellana, N.; Morales, P.; Olguín, Y.; Brown, D.I.; Enrione, J. Reepithelialization appraisal of skin wound in a porcine model using a salmon-gelatin based biomaterial as wound dressing. Pharmaceutics 2019, 11.

38. Chaudhary, C.; Garg, T. Scaffolds: a novel carrier and potential wound healer. Critical Reviews ${ }^{\mathrm{TM}}$ in $\begin{array}{llllll}\text { Therapeutic Drug } & \text { Carrier } & \text { Systems } & \text { 2015, } & 32, & \text { 277-321, }\end{array}$ https://doi.org/10.1615/critrevtherdrugcarriersyst.2015011246.

39. Zhu, Z.; Liu, Y.; Xue, Y.; Cheng, X.; Zhao, W.; Wang, J.; He, R.; Wan, Q.; Pei, X. Tazarotene released from aligned electrospun membrane facilitates cutaneous wound healing by promoting angiogenesis. ACS Appl. Mater. 2019, 11, 36141-36153, https://doi.org/10.1021/acsami.9b13271.

40. Bhattarai, N.; Edmondson, D.; Veiseh, O.; Matsen, F.A.; Zhang, M. Electrospun chitosan-based nanofibers and their cellular compatibility. Biomaterials 2005, 26, 6176-6184, https://doi.org/10.1016/j.biomaterials.2005.03.027.

41. Xu, T.; Yang, R.; Ma, X.; Chen, W.; Liu, S.; Liu, X.; Cai, X.; Xu, H.; Chi, B. Bionic Poly ( $\gamma$-Glutamic Acid) Electrospun Fibrous Scaffolds for Preventing Hypertrophic Scars. Adv. Healthc. Mater. 2019, 8, https://doi.org/10.1002/adhm.201900123.

42. Jayakumar, R.; Prabaharan, M.; Kumar, P.T.S.; Nair, S.V.; Tamura, H. Biomaterials based on chitin and chitosan in wound dressing applications. Biotechnol. Adv. 2011, 29, 322-337, https://doi.org/10.1016/j.biotechadv.2011.01.005.

43. Burkatovskaya, M.; Tegos, G.P.; Swietlik, E.; Demidova, T.N.; Castano, A.P.; Hamblin, M.R. Use of chitosan bandage to prevent fatal infections developing from highly contaminated wounds in mice. Biomaterials 2006, 27, 4157-4164, https://doi.org/10.1016/j.biomaterials.2006.03.028.

44. Ueno, H.; Mori, T.; Fujinaga, T. Topical formulations and wound healing applications of chitosan. Adv. Drug Deliv. Rev. 2001, 52, 105-115, https://doi.org/10.1016/S0169-409X(01)00189-2.

45. Verma, M.L.; Kumar, S.; Das, A.; Randhawa, J.S.; Chamundeeswari, M. Chitin and chitosan-based support materials for enzyme immobilization and biotechnological applications. Environ. Chem. Lett. 2020, 1-9, https://doi.org/10.1007/s10311-019-00942-5. 
46. Ketabchi, N.; Naghibzadeh, M.; Adabi, M.; Esnaashari, S.S.; Faridi-Majidi, R. Preparation and optimization of chitosan/polyethylene oxide nanofiber diameter using artificial neural networks. Neural. Comput. Appl. 2017, 28, 3131-3143, https://doi.org/10.1007/s00521-016-2212-0.

47. Mi, F.L.; Wu, Y.B.; Shyu, S.S.; Schoung, J.Y.; Huang, Y.B.; Tsai, Y.H.; Hao, J.Y. Control of wound infections using a bilayer chitosan wound dressing with sustainable antibiotic delivery. J. Biomed. Mater. Res. 2002, 59, 438-449, https://doi.org/10.1002/jbm.1260.

48. Di Martino, A.; Sittinger, M.; Risbud, M.V. Chitosan: a versatile biopolymer for orthopaedic tissueengineering. Biomaterials 2005, 26, 5983-5990, https://doi.org/10.1016/j.biomaterials.2005.03.016.

49. Khor, E.; Lim, L.Y. Implantable applications of chitin and chitosan. Biomaterials 2003, 24, 2339-2349, https://doi.org/10.1016/S0142-9612(03)00026-7.

50. Haider, S.; Al-Masry, W.A.; Bukhari, N.; Javid, M. Preparation of the chitosan containing nanofibers by electrospinning chitosan-gelatin complexes. Polym. Eng. Sci. 2010, 50, 1887-1893, https://doi.org/10.1002/pen.21721.

51. Rieger, K.A.; Birch, N.P.; Schiffman, J.D. Electrospinning chitosan/poly (ethylene oxide) solutions with essential oils: Correlating solution rheology to nanofiber formation. Carbohydr. Polym. 2016, 139, 131-138, https://doi.org/10.1016/j.carbpol.2015.11.073.

52. Zomer Volpato, F.; Almodóvar, J.; Erickson, K.; Popat, K.C.; Migliaresi, C.; Kipper, M.J. Preservation of FGF-2 bioactivity using heparin-based nanoparticles, and their delivery from electrospun chitosan fibers. Acta Biomaterialia 2012, 8, 1551-1559, https://doi.org/10.1016/j.actbio.2011.12.023.

53. Yang, Q.; Wang, B.; Zhang, Z.; Lou, D.; Tan, J.; Zhu, L. The effects of macromolecular crowding and surface charge on the properties of an immobilized enzyme: activity, thermal stability, catalytic efficiency and reusability. RSC Adv. 2017, 7, 38028-38036, https://doi.org/10.1039/C7RA06544B.

54. Grollmisch, A.; Kragl, U.; Großeheilmann, J. Enzyme Immobilization in Polymerized Ionic Liquids-based Hydrogels for Active and Reusable Biocatalysts. SynOpen 2018, 2, 0192-0199, https://doi.org/10.1055/s0037-1610144.

55. Das, R.; Talat, M.; Srivastava, O.; Kayastha, A.M. Covalent immobilization of peanut $\beta$-amylase for producing industrial nano-biocatalysts: A comparative study of kinetics, stability and reusability of the immobilized enzyme. Food Chem. 2018, 245, 488-499, https://doi.org/10.1016/j.foodchem.2017.10.092.

56. Sheldon, R.A. Enzyme immobilization: the quest for optimum performance. Adv. Synth. Catal. 2007, 349, 1289-1307, https://doi.org/10.1002/adsc.200700082.

57. Homaei, A.; Etemadipour, R. Improving the activity and stability of actinidin by immobilization on gold nanorods. Int. J. Biol. Macromol. 2015; 72, 1176-1181, https://doi.org/10.1016/j.ijbiomac.2014.10.029.

58. Ye, P.; Xu, Z.-K.; Wang, Z.-G.; Wu, J.; Deng, H.-T.; Seta, P. Comparison of hydrolytic activities in aqueous and organic media for lipases immobilized on poly (acrylonitrile-co-maleic acid) ultrafiltration hollow fiber membrane. J. Mol. Catal., B Enzym. 2005, 32, 115-121, https://doi.org/10.1016/j.molcatb.2004.11.005.

59. Cai, Z.-x.; Mo, X.-m.; Zhang, K.-h.; Fan, L.-p.; Yin, A.-1.; He, C.-1.; Wang, H.-s. Fabrication of chitosan/silk fibroin composite nanofibers for wound-dressing applications. Int. J. Mol. Sci. 2010; 11, 3529-3539. https://doi.org/10.3390/ijms11093529.

60. Wang, Z.-G.; Wan, L.-S.; Liu, Z.-M.; Huang, X.-J.; Xu, Z.-K. Enzyme immobilization on electrospun polymer nanofibers: an overview. J. Mol. Catal., B Enzym. 2009, 56, 189-195, https://doi.org/10.1016/j.molcatb.2008.05.005.

61. Kim, W.; Lee, J.S.; Shin, D.H.; Jang, J. Platinum nanoparticles immobilized on polypyrrole nanofibers for non-enzyme oxalic acid sensor. Mater Chem B. 2018, 6, 1272-1278, https://doi.org/10.1039/C7TB00629B.

62. Scheffel, D.L.S.; Bianchi, L.; Soares, D.G.; Basso, F.G.; Sabatini, C.; de Souza Costa, C.; Pashley, D.H.; Hebling, J. Transdentinal cytotoxicity of carbodiimide (EDC) and glutaraldehyde on odontoblast-like cells. Oper. Dent. 2015, 40, 44-54, https://doi.org/10.2341/13-338-L.

63. Christen, V.; Faltermann, S.; Brun, N.R.; Kunz, P.Y.; Fent, K. Cytotoxicity and molecular effects of biocidal disinfectants (quaternary ammonia, glutaraldehyde, poly (hexamethylene biguanide) hydrochloride PHMB) and their mixtures in vitro and in zebrafish eleuthero-embryos. Sci. Total Environ. 2017, 586, 1204-1218, https://doi.org/10.1016/j.scitotenv.2017.02.114.

64. Poursamar, S.A.; Hatami, J.; Lehner, A.N.; da Silva, C.L.; Ferreira, F.C.; Antunes, A.P.M. Gelatin porous scaffolds fabricated using a modified gas foaming technique: Characterisation and cytotoxicity assessment. Mater. Sci. Eng. C. 2015, 48, 63-70, https://doi.org/10.1016/j.msec.2014.10.074.

65. Anitha, A.; Sowmya, S.; Kumar, P.S.; Deepthi, S.; Chennazhi, K.; Ehrlich, H.; Tsurkan, M.; Jayakumar, R. Chitin and chitosan in selected biomedical applications. Prog. Polym. Sci. 2014, 39, 1644-1667, https://doi.org/10.1016/j.progpolymsci.2014.02.008.

66. Jayakumar, R.; Prabaharan, M.; Nair, S.; Tamura, H. Novel chitin and chitosan nanofibers in biomedical applications. Biotechnol. Adv. 2010, 28, 142-150, https://doi.org/10.1016/j.biotechadv.2009.11.001. 